\title{
REVISTAMARACANAN
}

\section{A cidade e suas imagens}

\author{
The city and its images
}

\section{Apresentação}

Amanda Danelli Costa*

Universidade do Estado do Rio de Janeiro

Teresópolis, Rio de Janeiro, Brasil

Carlos Eduardo Pinto de Pinto**

Universidade do Estado do Rio de Janeiro

Rio de Janeiro, Rio de Janeiro, Brasil

Viviane da Silva Araujo***

Universidade Federal da Integração Latino-

Americana

Foz do Iguaçu, Paraná, Brasil

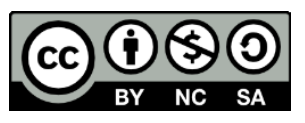

\footnotetext{
* Professora Adjunta do Instituto de Geografia da Universidade do Estado do Rio de Janeiro, Campus Teresópolis. Doutora e Mestre em História Social da Cultura pela Pontifícia Universidade Católica do Rio de Janeiro; graduada em História pela Universidade do Estado do Rio de Janeiro. (amanda.costa@uerj.br) Orcid iD: https://orcid.org/0000-0002-6845-4733

Lattes: http://lattes.cnpq.br/1855259803755979
}

** Professor Adjunto do Instituto de Filosofia e Ciências Humanas da Universidade do Estado do Rio de Janeiro, atuando na graduação e no Programa de Pós-graduação em História. Doutor em História pela Universidade Federal Fluminense; Mestre em História Social da Cultura pela Pontifícia Universidade Católica do Rio de Janeiro; graduado em História pela Universidade do Estado do Rio de Janeiro. (carlos.pinto@uerj.br)

Orcid iD: https://orcid.org/0000-0001-7448-2565

Lattes: http://lattes.cnpq.br/2703751377441692

*** Professora Adjunta do Instituto Latino-Americano de Arte, Cultura e História da Universidade Federal da Integração Latino-Americana. Doutora e Mestre em História Social da Cultura pela Pontifícia Universidade Católica do Rio de Janeiro; graduada em História pela Universidade do Estado do Rio de Janeiro. (viviane.araujo@unila.edu.br)

Orcid iD: https://orcid.org/0000-0001-7378-0210

Lattes: http://lattes.cnpq.br/5388549060655237 
A definição de "cidade" e "imagem" não é tarefa epistemológica simples e o cruzamento das apreensões já propostas pode levar a um labirinto tão desafiador quanto atraente. São duas coordenadas complexas, cujas relações desenham planos intrincados, exigindo uma abordagem multidisciplinar. O que define uma cidade? Seu tamanho, suas formas, suas funções, seu contingente populacional? Suas redes de cultura? O que é uma imagem e quanta informação ou material sensível cabe numa tela, num quadro, num muro?

Os coordenadores deste dossiê, pesquisando diferentes temas, se formaram a partir dessas miradas sobre a cidade e suas imagens, expressas nas suas teses de doutoramento. Amanda Danelli Costa investigou as reformas urbanas e a modernidade carioca a partir das obras, literária e fotográfica, de João do Rio e Augusto Malta. Enquanto o cronista elaborava interpretações e representações do Rio de Janeiro, disputando a narrativa moderna da cidade nos periódicos; Augusto Malta inventariava as transformações da urbes, assentado em uma tradição ilustrada, tanto do ponto de vista técnico quanto pela referência civilizadora vinculada ao urgente progresso material urbano. ${ }^{1}$

Carlos Eduardo Pinto de Pinto abordou a representação da cidade do Rio de Janeiro pelo Cinema Novo entre 1955 e 1970, abarcando o surgimento das ideias que embasariam o movimento nos anos 1960, bem como suas mutações ao longo da década. A vinculação do Cinema Novo à vivência urbana carioca define um de seus perfis e fornece elementos para a elaboração de imaginários sociais na e sobre a cidade. Capital federal até 1960, o Rio começou a década sendo transformado em Estado da Guanabara, depois de perder o posto de cabeça do país para Brasília. Ainda assim, a capitalidade foi o eixo norteador das obras analisadas, que mobilizam duas estratégias de representação: a oposição da modernidade urbana às mazelas sociais, caso de Rio, 40 graus, Cinco vezes favela e $A$ grande cidade; ou a evocação da capitalidade em sua relação com os traços identitários da jovem classe média, como Os cafajestes, O desafio, Garota de Ipanema e Todas as mulheres do mundo. Através de agenciamentos diversos, os atores sociais abordados pela pesquisa - profissionais envolvidos nas produções dos filmes, críticos, teóricos, políticos e outros - se apropriaram das obras, pondo em disputa os imaginários urbanos e as práticas sociais. ${ }^{2}$

Viviane da Silva Araujo investigou como as transformações urbanas ocorridas em Buenos Aires e no Rio de Janeiro na passagem do século XIX para o XX tornaram-se temas para fotógrafos locais e estrangeiros. Analisando as duas cidades comparativamente, a tese identifica na produção fotográfica algumas das tensões próprias à experiência da modernidade urbana latino-americana, onde o desejo de adequar-se a um modelo ideal de civilização não foi capaz de produzir uma sociedade ordenada segundo os preceitos do almejado progresso

${ }^{1}$ COSTA, Amanda Danelli. Cidade, reformas urbanas e modernidade: o Rio de Janeiro em diálogo com João do Rio e Augusto Malta. 2011. Tese (Doutorado em História Social da Cultura) - Pontifícia Universidade Católica do Rio de Janeiro, Rio de Janeiro.

2 PINTO, Carlos Eduardo Pinto de. Imaginar a cidade real: o Cinema Novo e a representação da modernidade urbana carioca (1955-1970). 2013. Tese (Doutorado em História) - Instituto de Ciências Humanas e Filosofia da Universidade Federal Fluminense, Niterói (RJ). 
material e moral, mas experimentou uma realidade imprevista, original e complexa. Realidade esta que a fotografia não só captou, mas contribuiu para criar maneiras de imaginar, ver e sentir ambas as cidades em acelerado processo de transformação naquele período. ${ }^{3}$

Frequentemente, e desde há muito tempo, as urbes vêm sendo tematizadas por diferentes imagens ${ }^{4}$ - dos registros cartográficos às mídias digitais, passando pelas artes plásticas, fotografia, cinema, TV, vídeo, grafite e pichação - produzindo representações que alargaram as possibilidades de interpretação e produção de sentidos sobre as cidades, vistas em perspectiva histórica. Desse modo, as cidades em ampliação e transformação foram largamente fixadas em imagens cada vez mais várias e complexas, um processo que não ficou de fora do conjunto de interesses dos historiadores.

Observadas a partir da modernidade, cidade e imagem também ensejaram reflexões sobre a subjetividade moderna e as novas formas de estar no mundo, interpretá-lo e representá-lo. ${ }^{5}$ A invenção da fotografia, na primeira metade do século XIX, facilmente associada à consequente mudança do padrão de visualidade, só se efetivou como um invento possível em razão de uma transformação da própria subjetividade moderna na passagem do século XVIII para o XIX. ${ }^{6}$ As grandes cidades, que enfrentaram o frenesi da revolução urbana oitocentista, foram os palcos principais para esse novo "observador de segunda ordem". ${ }^{7}$ Sujeitos e cidades eram, enfim, atravessados e traduzidos pelo registro da reprodutibilidade técnica. $^{8}$

Movimento semelhante pode ser observado nas relações entre cidades e cinema, que tem interessado, sobretudo, à historiografia norte-americana e francesa. De modo geral, os americanos focam a importância simultânea da cidade e do cinema para a conformação da modernidade, enquanto os franceses privilegiam a representação do urbano pelos filmes. ${ }^{9}$ Entre a produção francesa, cabe destacar, além das obras homônimas La ville au cinéma, também Visions urbaines, Cités-cinés, Ville et cinéma e Un nouvel art de voir la ville et de faire du cinéma. ${ }^{10}$ Nessas obras, a maioria formada por reunião de artigos, é flagrante o recurso à interdisciplinaridade, havendo contribuição de historiadores, cineastas, críticos, cenógrafos, antropólogos, sociólogos, linguistas, comunicólogos, arquitetos e urbanistas. Por mais que sejam variadas as abordagens, todas confluem na crença de que os filmes urbanos não

\footnotetext{
${ }^{3}$ ARAUJO, Viviane da Silva. Fragmentos urbanos da modernidade: a fotografia em Buenos Aires e no Rio de Janeiro na passagem do século XIX para o XX. 2013. Tese (Doutorado em História Social da Cultura) Pontifícia Universidade Católica do Rio de Janeiro, Rio de Janeiro.

${ }^{4}$ SONTAG, Susan. Sobre a fotografia. São Paulo: Companhia das Letras, 2004.

5 CRARY, Richard. Técnicas do observador: visão e modernidade no século XIX. Rio de Janeiro: Contraponto, 2012.

${ }^{6}$ FOUCAULT, Michel. As palavras e as coisas. São Paulo: Martins Fontes, 2016.

7 GUMBRECHT, Han Ulrich. Modernização dos sentidos. São Paulo: Editora 34, 1998.

${ }^{8}$ BENJAMIN, Walter. A obra de arte na era de sua reprodutibilidade técnica. Porto Alegre: L\&PM, 2013.

9 CHARNEY, Leo; SCHWARTZ, Vanessa R. (orgs.). O cinema e a invenção da vida moderna. São Paulo: Cosac \& Naify, 2001.

10 JOUSSE, Thierry; PAQUOT, Thierry (dir.). La ville au cinéma: encyclopédie. Paris: Cahiers du Cinéma, 2005; BARILLET, Julie; et al. La ville au cinéma. Arras: Artois Presses Université, 2005; NINEY, François (dir.). Visions urbaines: villes d'Europe a l'ecran. Paris: Éd. Centre Pompidou, 1994; Cités-cinés. Paris: Éd. Ramsay et La Grande Halle; La Villete, 1997. [édité à I'occasion de l'exposition Cités-Cinés]; Espaces et Societes, Paris, L'Harmattan, 86 - "Ville et cinéma", 1996.
} 
oferecem um acesso direto às cidades, sendo, ao contrário, considerados reinvenções destas, ao mesmo tempo em que constituem suas realidades.

Se por um lado observamos a multiplicação de pesquisas que tomavam os registros imagéticos, especialmente depois da criação da fotografia - e, mais tarde, do cinema - como fontes para a análise das transformações urbanas, dos códigos sociais e das sociabilidades, mais recentemente se tornaram frequentes os trabalhos que vão às cidades para compreenderem como diferentes grupos produzem registros variados no próprio corpo da urbes, criando imagens (pichações, grafites, estênceis) que revelam distintas urbanidades, relações de poder e apropriação possíveis.

A fotografia e o cinema também assumem relação forte e estreita com a memória, seja de indivíduos, grupos sociais ou de cidades. ${ }^{11}$ Suas dinâmicas de recorte de um tempo e espaço, que sobrevive para além do momento do clique e da filmagem, contribuiu vivamente para que frequentemente assumam papel de gatilho ou ponto de partida para a memória. Aquilo que aqui chamamos de dinâmica própria da fotografia e o específico fílmico também se aproximam da maneira como a memória se organiza: seja em uma foto, em um filme, ou seja, com a memória, é impossível lembrar tudo ou colocar tudo dentro do quadrado. ${ }^{12}$ Os três implicam seleção, esquecimento e tomadas de pontos de vista. ${ }^{13}$

Na Europa, abordagens dessa natureza foram iniciadas nos anos 1960, pela Nova História Urbana, tendo Richard Sennett como figura mais proeminente, e pela História da Arte, com destaque para Giulio Carlo Argan. ${ }^{14}$ Como alternativa a abordagens que equacionam o objeto "cidade" a processos de urbanização (dimensões, formas, funcionalidades), tais enfoques privilegiam as cidades como objetos singulares, atuando como centro geradores de identidades. ${ }^{15}$ Argan, por exemplo, defende que a cidade seja um acúmulo de bens culturais (incluindo-se as imagens) e não apenas "o produto das técnicas de construção [que] também concorrem para determinar a [sua] realidade visível". ${ }^{16}$

O papel da cidade como o locus a partir do qual se imagina, projeta e se representa a experiência moderna e sua realidade visível também esteve no cerne da reflexão de estudiosos latino-americanos neste mesmo período. Em 1976, o historiador argentino José Luis Romero publica sua mais importante obra, cujo subtítulo, "as cidades e as ideias", já expõe a permanente tensão entre a cidade real e a cidade imaginada. Tal argumento é desenvolvido mais tarde por pesquisadores como Adrián Gorelik, que adverte que a modernidade urbana

\footnotetext{
11 PINTO, Carlos Eduardo Pinto de. Câmera-arma: a representação das funções sociais da fotografia em Os cafajestes (Ruy Guerra, 1962). Revista Brasileira de História da Mídia, São Paulo, v. 2, n. 2, p. 151158, jul.-dez. 2013.

12 PINTO, Carlos Eduardo Pinto de. Relatos fantasmas: os filmes históricos cinemanovistas e a política cultural da ditadura civil-militar nos anos 1970. REBECA - Revista Brasileira de Estudos de Cinema e Audiovisual, São Paulo, v. 2, n. 1, jan.-jun. 2013.

${ }^{13}$ COSTA, Amanda Danelli. Augusto Malta e a fotografia da alma dos kiosques cariocas. Acervo, Rio de Janeiro, Arquivo Nacional, v. 32, n. 2, p. 117-132, maio-ago. 2019.

14 SENNETT, Richard. Carne e pedra: o corpo e a cidade na civilização ocidental. Rio de Janeiro: Record, 1999; ARGAN, Giulio Carlo. História da arte como história da cidade. São Paulo: Martins Fontes, 1992.

15 SILVA, Luís Octávio da. História urbana: uma revisão da literatura epistemológica em inglês. EURE, Santiago, v. 28, n. 83, maio 2002.

${ }^{16}$ ARGAN, Giulio Carlo. História da arte... Op. cit., p. 75.
} 
experimentada na América Latina foi original e complexa e, se comparada às seculares cidades europeias, a cidade latino-americana não decorre dos processos de modernização, mas antecipa a eles, como um instrumento capaz de "criar" uma sociedade moderna. ${ }^{17}$

No Brasil, pesquisas que relacionam cidade, modernidade e imagem ganharam força a partir dos anos 1980, convivendo com uma produção - naquele momento, mais vasta - a respeito das relações entre cidade e literatura. Eram, na sua maioria, reflexões sobre registros fotográficos realizados nas primeiras décadas do século XX nas cidades do Rio de Janeiro, São Paulo e Porto Alegre, resultados das pesquisas de mestrado e doutorado de Ana Maria Mauad, Maria Inez Turazzi, Vânia Carneiro de Carvalho e de Charles Monteiro. Desde então, multiplicaram-se os enfoques, com uma seleção variegada de urbes, tipos de imagens e recortes cronológicos. ${ }^{18}$

O encontro entre o urbano e o imagético por meio da análise de uma variedade de cidades, reais e imaginárias, e de imagens dos mais diferentes suportes, está presente nos 18 artigos e na entrevista que compõem a presente edição da Revista Maracanan. O número expressivo de submissões que atenderam à chamada nos alegrou, ao demonstrar a potencialidade do tema. Esperamos que a publicação deste dossiê contribua para o reconhecimento e a ampliação das abordagens e significados teórico-metodológicos a respeito das interfaces entre cidade e imagem.

A entrevista que abre o dossiê foi realizada ao longo de uma noite muito agradável na companhia (virtual) de Ana Maria Mauad. A pesquisadora e professora nos apresentou um vasto panorama a respeito das relações entre as cidades e suas imagens, centrando-se nos trabalhos sobre fotografia, tema da maioria de suas pesquisas, mas alcançando também outros suportes. O registro dessa conversa dá acesso a um vislumbre dos caminhos percorridos por uma das primeiras historiadoras, no Brasil, a se dedicar às relações entre história e imagem.

Entre os artigos que compõem o dossiê, a estereoscopia e o seu desenvolvimento no Brasil, entre 1850 e 1950, são apresentados por Maria Isabela Mendonça dos Santos a partir dos acervos de fotógrafos profissionais e amadores que produziram uma variedade de vistas de cidades brasileiras, contribuindo para a formação e divulgação de uma imagem do Brasil, exótica e civilizada, enquanto redimensionava a própria subjetividade moderna pelo olhar. A produção amadora de estereoscopias de Guilherme Antonio dos Santos por mais de cinquenta anos, resultando em um acervo particularmente extenso, é objeto de análise neste

17 ROMERO, José Luís. América Latina: as cidades e as ideias. Rio de Janeiro: Ed. UFRJ, 2009; GORELIK, Adrián. Ciudad, modernidad, modernización. Universitas Humanística, Bogotá, Pontificia Universidad Javeriana, n. 56, jun. 2003.

18 MAUAD, Ana Maria. Sob o signo da imagem: a produção da fotografia e o controle dos códigos de representação social, na cidade do Rio de Janeiro na primeira metade do século XX. 1990 . Tese (Doutorado em História) - Universidade Federal Fluminense, Niterói (RJ); TURAZZI, Maria Inez. As artes do ofício: fotografia e memória da engenharia no século XIX. 1998. Tese (Doutorado em Arquitetura e Urbanismo) - Universidade de São Paulo, São Paulo; CARVALHO, Vânia Carneiro de. Do indivíduo ao tipo: as imagens da (des)igualdade nos álbuns fotográficos da cidade de São Paulo na década de 1950. 1995. Dissertação (Mestrado em História) - Universidade de São Paulo, São Paulo; MONTEIRO, Charles. $A$ inscrição da modernidade no espaço urbano de Porto Alegre. 1992. Dissertação (Mestrado em História) Pontifícia Universidade Católica do Rio Grande do Sul, Porto Alegre. 
artigo que observa a produção de imagens sobre a cidade do Rio de Janeiro como artifícios da construção de uma paisagem ideal.

Em diálogo com o campo da história pública, Michel Kobelinski analisa pinturas, gravuras, fotografias e narrativas - entendidas aqui como lugares de memória - produzidas por Estanislau Schaette, Hermann Schiefelbein, Arthur Wischral e Hugo Hegenberg sobre a identidade teuto-brasileira e seus efeitos na sociedade paranaense na primeira metade do século XX. Essas obras são tomadas por seu caráter pedagógico que, além de educar sobre 0 passado, contribuiu para a aproximação com histórias plurais e ainda para a produção de vínculos coletivos.

O artigo de Samuel Oliveira aborda fotorreportagens que tematizam a favela publicadas na revista $O$ Observador Econômico e Financeiro - especializada em análises econômicas e sociais e articulada ao projeto desenvolvimentista das décadas de 1940 e 1950 . Em sua análise, demonstra como tais matérias reiteraram os estigmas da pobreza urbana e sua racialização por meio dos registros fotográficos das favelas cariocas e dos contrastes estabelecidos com o padrão de vida da classe média.

Em artigo que analisa a Primeira Exposição Fotográfica de Motivos Belorizontinos, ocorrida em 1953, fruto de uma parceria entre o Foto Clube de Minas Gerais e a Prefeitura de Belo Horizonte, Lucas Mendes Menezes investiga relações entre fotografia amadora e poder público. Além da análise da composição visual de fotografias reproduzidas no catálogo desta exposição, o autor explora o olhar que os fotógrafos lançaram sobre a cidade - especialmente sobre os seus elementos arquitetônicos - assim como seus condicionamentos e espaços de atuação, entendendo a fotografia no conjunto das iniciativas culturais do período e suas interseções com o poder público.

Débora Bueno, Ricardo Freitas \& Vania Fortuna investigam as fotografias de César Barreto, tomando-as como elementos constitutivos da memória urbanística da cidade do Rio de Janeiro. Fotógrafo oficial da "cidade olímpica", coube a César Barreto documentar, entre 2011 e 2013, as reformas que a cidade enfrentava para abrigar os Jogos Olímpicos de 2016. As fotografias publicadas em um portal institucional eram peças imagéticas centrais no processo de valorização da marca-cidade, a fim de torná-la mais competitiva no concorrido mercado internacional de cidades globais. Mais do que registrar o processo de revitalização da zona portuária, como quem guarda as lembranças do que fora a cidade, as fotografias de César Barreto apontavam para o futuro olímpico do Rio de Janeiro, como destino incontornável da cidade maravilhosa.

Utilizando a metodologia de leitura da imagem da cidade de Kevin Lynch, Paulo Barata identifica o acúmulo de tempos desiguais presentes no centro comercial de Campo Grande, bairro do subúrbio do Rio de Janeiro, no século XXI. O autor nos convida a observar com detalhes como esta localidade outrora rural apresenta hoje uma paisagem tipicamente urbana.

A cultura midiática da Belle Époque carioca é desnudada por Carmem Lúcia Negreiros de Figueiredo Souza, que analisa como as crônicas literárias registraram novos modos de ver e narrar a cidade no contato com os novos aparatos e imagens - produzidas pelo cinema, 
pela imprensa e expostas em vitrines -, afetando a constituição e a percepção dos sujeitos modernos, expressas nas transformações das sociabilidades e sensibilidades das primeiras décadas do século XX. As crônicas de João do Rio, Olavo Bilac, Benjamin Costallat e Lima Barreto são, neste artigo, exemplos da renovação representativa e da alteração na estrutura de percepção dos sujeitos modernos, revelando a tensão entre o imaginário literário e o imaginário técnico.

Wolney Vianna Malafaia aborda o Rio de Janeiro a partir da oferta de condições materiais e intelectuais para a formação do Cinema Novo brasileiro. Embora aponte alguns traços de representação da cidade em dada filmografia cinemanovista, a proposta principal do autor é pensar a cidade como catalisadora do movimento cinematográfico, ao longo dos anos 1960. Por meio do levantamento de instituições e redes de sociabilidade, o trabalho demonstra o quanto aquela, que até há pouco tinha sido capital do Brasil, seguiu exercendo funções associadas à capitalidade.

Francisco das Chagas Fernandes Santiago Júnior analisa o filme Notas para uma Oréstia Africana (Appunti per un'Orestiade Africana, Pier Paolo Pasolini, 1969), com vistas a compreender a construção visual das paisagens urbanas e naturais de alguns países africanos no documentário do diretor italiano. Para o enfrentamento do específico fílmico, o autor mobiliza a iconologia, a narratologia histórica e a abordagem filmológica, problematizando o estatuto sócio-histórico das imagens, evidenciando os mecanismos empregados na construção do filme e cruzando os resultados com os escritos sobre cinema.

Mauro Amoroso \& Gustavo Romano propõem uma abordagem heurística do modo como o Jornal do Brasil (JB) e o filme Cidade de Deus (Fernando Meirelles e Kátia Lund, 2002) narraram eventos relacionados à "guerra" da Cidade de Deus, conflitos entre traficantes ocorridos na virada da década de 1970 para a de 1980. Em suas análises, os autores levam em consideração a especificidade da linguagem de cada veículo, bem como os diferentes contextos históricos, elencando os elementos constitutivos de cada modo de "ler" ou "ver" os eventos.

Fabio Allan Mendes Ramalho assume perspectiva benjaminiana ao analisar os corpos em perambulação por espaços urbanos, tomados como lugares de encontro afetivo e desejo (homo)erótico. Por meio da análise de três filmes de Marcelo Caetano - Bailão (2009), Na sua companhia (2011) e Corpo elétrico (2017) -, o autor demonstra como a linguagem cinematográfica é capaz de reelaborar, mais do que registrar, a materialidade urbana em consonância com a vivência sexual e afetiva das personagens.

Leonardo Perdigão Leite \& Pedro Jorge Lo Duca Vasconcelos investigam novas práticas museais e museológicas na cidade do Rio de Janeiro - o Museu de Favela PavãoPavãozinho Cantagalo, a Galeria Providência e o Museu Nami - observando como essas iniciativas se baseiam em visões não ortodoxas de patrimônio, memória e museu. Tais experiências produzem alternativas aos modelos tradicionais e consagrados, apoiadas em uma museologia social, comunitária, popular, informal ou progressista, contribuindo para a construção de outros modos de expressão a partir da subjetivação (reveladas através de 
grafites, estênceis, murais, painéis) de grupos subalternizados, no lugar de promover a cristalização de identidades.

O grafite é tematizado por Ivânia dos Santos Neves que toma o aniversário de 400 anos de Belém como um período favorável para a reflexão sobre os discursos que forjaram a história oficial da cidade, uma história escrita pelo colonizador, como de tantas cidades latinoamericanas, mas que exibe suas fraturas quando movimentos indígenas e outros enunciadores artístico-culturais conquistam espaço na dinâmica de contar a história. Ao contrapor o frontal da Basílica de Nazaré e a escultura de bronze de um indígena de um bairro nobre de Belém e os grafites de artistas locais que retomam a memória indígena em suas produções e visibilizam a pluralidade étnica da cidade, a autora mostra como o grafite visibiliza a presença indígena silenciada no patrimônio oficial.

Ana Paula Alves Ribeiro propõe uma abordagem etnográfica da peça teatral In_Trânsito, encenada pela Cia. Marginal e com direção de Isabel Penoni e Joana Levi, entre 2013 e 2014. Trata-se de uma performance site-specific, partindo da Central do Brasil e estendendo-se por paisagens urbanas fruídas ao longo do percurso ferroviário. O registro da vivência dos múltiplos estímulos propiciados pela experiência, com ênfase nos elementos visuais, permite à autora pensar o Rio de Janeiro em um biênio marcado pelas lutas urbanas manifestadas, entre outras possibilidades, no artivismo (ativismo político executado por meio de ações artísticas).

A sessão de artigos livres também traz trabalhos que abordam o tema da cidade e de suas representações. Propostos para além da análise de suportes imagéticos propriamente ditos, são estudos que igualmente colaboram para ampliar o conhecimento sobre a elaboração de imaginários urbanos e de imagens ideais das cidades em distintos espaços e momentos históricos.

Nesse bojo, o Rio de Janeiro, cidade a partir da qual a Revista Maracanan se comunica com o mundo acadêmico, teve sua gênese marcada por uma disputa de ideais de cidade, o que resultou em tensões em torno da sua dupla fundação, francesa e portuguesa. Apesar da crise que o Estado moderno impôs às individualidades e às cidades-republicanas, a projeção das utopias levadas a frente significava uma resistência do próprio ideal de cidade moderna, de modo que "a noção de utopia qualificava criticamente o desempenho dos homens na cidade projetando-a para fora do espaço real". ${ }^{19}$

Assim, chegamos ao entendimento de que a cidade, além de recorrentemente aparecer como tema de interesse dos homens de letras desde as fundações das primeiras cidades latino-americanas, significava para eles o lugar primordial - e também inescapável - no qual viveriam a experiência da modernidade, de tal forma que era a partir dessa dupla referência (cidade/modernidade) que eles se constituíram como sujeitos no mundo e, por conseguinte,

\footnotetext{
${ }^{19}$ RODRIGUES, Antonio Edmilson Martins. América Renascentista- um ensaio: as experiências modernas no espaço da Baía de Guanabara - a dupla fundação da cidade do Rio de Janeiro: entre utopias e ideais. MORUS, Campinas (SP), UNICAMP, v. 3, p. 213-242, 2006.
} 
refletiram sobre a modernidade na cidade. ${ }^{20}$ Nesse sentido, como já apontado acima, a experiência moderna nas cidades latino-americanas foi o trampolim para que se produzissem as condições de modernização desses espaços, de suas relações sociais e políticas, bem como de suas representações, de modo que "a modernidade se impôs como parte de uma política deliberada para conduzir à modernização, e nessa política a cidade foi o objeto privilegiado". ${ }^{21}$

Fabrina Magalhães Pinto apresenta uma leitura da Laudatio de Leonardo Bruni no quattrocento, observando em particular os debates acerca dos ideais republicanos de liberdade, autogoverno e cidadania, neste que é um dos principais elogios da cidade de Florença no período. Entre os séculos XII e XV, Florença, como lócus privilegiado da ação do homem renascentista, experimentou a construção paulatina de um ideal de cidade, fosse no âmbito arquitetônico, político ou das instituições. Nesse momento se conjugaram ambições republicanas com a construção de uma imagem ideal de cidade, onde justiça, racionalidade e liberdade estariam em destaque.

Andréa Cristina de Barros Queiroz nos apresenta o panorama da construção da "República de Ipanema", como um lugar de vanguarda no Rio de Janeiro, durante os anos 1960. A imagem de cidade maravilhosa fora atualizada por uma boemia-literária a partir das sociabilidades vividas em diferentes espaços de encontro no bairro de Ipanema, como os bares e a praia. Além disso, atribuiu-se ao bairro a condição de polo difusor de uma série de movimentos políticos, sociais e culturais que ocuparam a cena de oposição aos anos de ditadura civil-militar.

A imagem da cidade de Brasília lida como cidade utópica e ícone do desenvolvimentismo brasileiro nos anos 1950 e 1960 ainda se apresenta como a imagem hegemônica da capital federal. No entanto, Lucía Tennina revela-nos a construção de novas miradas sobre a cidade e a partir dela nos saraus das periferias. Espaços contra-hegemônicos, os saraus exploram temas e tensões que transbordam das margens dos enquadramentos apaziguados do Plano Piloto. O cartão postal, expressão da imagem desejável, é a metáfora escolhida para nos falar das pluralidades que não cabem em uma história única.

Hércules da Silva Xavier Ferreira, Luana Campos \& Pedro Clerot analisam uma série de grafites e uma escultura que evocam as imagens de três jovens assassinados no Rio de Janeiro em 1998, 2005 e 2017 nas proximidades do túnel Santa Bárbara, que conformaram o que os autores definem como "polígono da violência" ou "circuito da dor". A criação desses memoriais permite que os transeuntes, moradores ou não da cidade, vejam e sejam afetados pelo conhecimento dessas histórias, ao mesmo tempo em que ressignificam o sofrimento e conformam espaços de resiliência.

Esperamos que a leitura dos artigos deste número da Revista Maracanan contribua para a ampliação de debates e pesquisas interessadas no cruzamento das cidades e suas imagens.

${ }^{20}$ COSTA, Amanda Danelli. A produção de guias de viagem por intelectuais brasileiros: um ensaio. In: MARAFON, Glaucio; FACCIOLI, Marina; SÁNCHEZ, Meylin Alvarado. Patrimônio, território e turismo no Brasil, Costa Rica e Itália. Rio de Janeiro: EdUERJ, 2020.

${ }^{21}$ GORELIK, Adrián. Ciudad, modernidad, modernización. Op. cit., p. 13. Tradução nossa. No original: "la modernidad se impuso como parte de una política deliberada para conducir a la modernización, y en esa política la ciudad fue el objeto privilegiado". 
Fazemos votos de que o contato com esses textos seja tão instigante e prazeroso para os leitores da revista quanto foi para nós. 


\section{Referências}

ARAUJO, Viviane da Silva. Fragmentos urbanos da modernidade: a fotografia em Buenos Aires e no Rio de Janeiro na passagem do século XIX para o XX. 2013. Tese (Doutorado em História Social da Cultura) - Pontifícia Universidade Católica do Rio de Janeiro. Rio de Janeiro.

ARGAN, Giulio Carlo. História da arte como história da cidade. São Paulo: Martins Fontes, 1992.

BARILLET, Julie; et al. La ville au cinéma. Arras: Artois Presses Université, 2005.

BENJAMIN, Walter. A obra de arte na era de sua reprodutibilidade técnica. Porto Alegre: L\&PM, 2013.

CARVALHO, Vânia Carneiro de. Do indivíduo ao tipo: as imagens da (des)igualdade nos álbuns fotográficos da cidade de São Paulo na década de 1950. 1995. Dissertação (Mestrado em História) - Universidade de São Paulo, São Paulo.

CHARNEY, Leo; SCHWARTZ, Vanessa R. (orgs.). O cinema e a invenção da vida moderna. São Paulo: Cosac \& Naify, 2001.

Cités-cinés. Paris: Éd. Ramsay et La Grande Halle; La Villete, 1997. [édité à I'occasion de l'exposition Cités-Cinés].

COSTA, Amanda Danelli. A produção de guias de viagem por intelectuais brasileiros: um ensaio. In: MARAFON, Glaucio; FACCIOLI, Marina; SÁNCHEZ, Meylin Alvarado. Patrimônio, território e turismo no Brasil, Costa Rica e Itália. Rio de Janeiro: EdUERJ, 2020.

COSTA, Amanda Danelli. Augusto Malta e a fotografia da alma dos kiosques cariocas. Acervo, Rio de Janeiro, Arquivo Nacional, v. 32, n. 2, p. 117-132, maio-ago. 2019.

COSTA, Amanda Danelli. Cidade, reformas urbanas e modernidade: o Rio de Janeiro em diálogo com João do Rio e Augusto Malta. 2011. Tese (Doutorado em História Social da Cultura) - Pontifícia Universidade Católica do Rio de Janeiro, Rio de Janeiro.

Espaces et Societes, Paris, L'Harmattan, 86 - "Ville et cinéma", 1996.

FOUCAULT, Michel. As palavras e as coisas. São Paulo: Martins Fontes, 2016.

GORELIK, Adrián. Ciudad, modernidad, modernización. Universitas Humanística, Bogotá, Pontificia Universidad Javeriana, n. 56, jun. 2003.

GUMBRECHT, Han Ulrich. Modernização dos sentidos. São Paulo: Editora 34, 1998.

JOUSSE, Thierry; PAQUOT, Thierry (dir.). La ville au cinéma: encyclopédie. Paris: Cahiers du Cinéma, 2005.

MAUAD, Ana Maria. Sob o signo da imagem: a produção da fotografia e o controle dos códigos de representação social, na cidade do Rio de Janeiro na primeira metade do século XX. 1990. Tese (Doutorado em História) - Universidade Federal Fluminense, Niterói (RJ).

MONTEIRO, Charles. A inscrição da modernidade no espaço urbano de Porto Alegre. 1992. Dissertação (Mestrado em História) - Pontifícia Universidade Católica do Rio Grande do Sul, PUCRS, Porto Alegre.

NINEY, François (dir.). Visions urbaines: villes d'Europe a l'ecran. Paris: Éd. Centre Pompidou, 1994. 
PINTO, Carlos Eduardo Pinto de. Câmera-arma: a representação das funções sociais da fotografia em Os cafajestes (Ruy Guerra, 1962). Revista Brasileira de História da Mídia, São Paulo, v. 2, n. 2, p. 151-158, jul.-dez. 2013.

PINTO, Carlos Eduardo Pinto de. Imaginar a cidade real: o Cinema Novo e a representação da modernidade urbana carioca (1955-1970). 2013. Tese (Doutorado em História) - Instituto de Ciências Humanas e Filosofia da Universidade Federal Fluminense, Niterói (RJ).

PINTO, Carlos Eduardo Pinto de. Relatos fantasmas: os filmes históricos cinemanovistas e a política cultural da ditadura civil-militar nos anos 1970. REBECA - Revista Brasileira de Estudos de Cinema e Audiovisual, São Paulo, v. 2, n. 1, jan.-jun. 2013.

RODRIGUES, Antonio Edmilson Martins. América Renascentista- um ensaio: as experiências modernas no espaço da Baía de Guanabara - a dupla fundação da cidade do Rio de Janeiro: entre utopias e ideais. MORUS, Campinas (SP), UNICAMP, v. 3, p. 213-242, 2006.

ROMERO, José Luís. América Latina: as cidades e as ideias. Rio de Janeiro: EdUFRJ, 2009.

SENNETT, Richard. Carne e pedra: o corpo e a cidade na civilização ocidental. Rio de Janeiro: Record, 1999.

SILVA, Luís Octávio da. História urbana: uma revisão da literatura epistemológica em inglês. EURE, Santiago, v. 28, n. 83, maio 2002.

SONTAG, Susan. Sobre a fotografia. São Paulo: Companhia das Letras, 2004.

TURAZZI, Maria Inez. As artes do ofício: fotografia e memória da engenharia no século XIX. 1998. Tese (Doutorado em Arquitetura e Urbanismo) - Universidade de São Paulo, São Paulo. 